\title{
Nitrogen and Phosphorus Treatment from Dormitory Wastewater of Srinakharinwirot University Ongkaruk by Acrostichumaureum L. and Eucalyptus globulus Labill.
}

\author{
Jirawan Torit
}

\begin{abstract}
Contaminated nutrients in wastewater is critical problem of worldwide. The aim of this study was nitrogen and phosphorus treatment from dormitory wastewater of Srinakharinwirot University Ongkaruk by Acrostichumaureum L. and Eucalyptus globulus Labill. The plants were cultured in the pot and treated wastewater for 4 cycles. The differed plant weight was compared the efficiency in nitrogen and phosphorus treatment. The result found that Eucalyptus globulus Labill which is perennial plant had better efficiency in nitrogen and phosphorus treatment than Acrostichumaureum $\mathrm{L}$. which is aquatic plant. The plant could grow well in wastewater and removed nutrients until passed standard criteria for short time. Moreover, plant biomass increased after nitrogen and phosphorus treatment for one month. These results showed the sustainable system in nutrients treatment from wastewater. Eucalyptus globulus Labill is new selected plant to remove nutrients and suit to apply for nitrogen and phosphorus treatment from wastewater.
\end{abstract}

Keywords-nitrogen, phosphorus, wastewater treatment, Acrostichumaureum L., Eucalyptus globulus Labill.

\section{Introduction}

Excessive nitrogen and phosphorus in water bodies is a critical problem of worldwide. These nutrients contaminated in aquatic ecosystem result in eutrophication [1]. Nitrogen and phosphorus are discharged from municipal, agricultural and industrial effluent [2]. Nitrogen and phosphorus contaminated in several sources such as lakes, rivers, reservior, and coastal waters. Especially, the most of these nutrients is contaminated in domestic wastewater of Thailand [3]. Eutrophication induce to the toxic algal bloom, low oxygen and dead of aquatic animals [4]. There are many methods to remove nutrients from wastewater is physical and chemical methods. However, these method disadvantages are high cost of operation and low efficiency for nitrogen and phosphorus treatment. Therefore, phytoremediation is alternative method to remove these nutrients because of lower cost, easier to operate system, and environmentally friendly [5]. Moreover, nitrogen and phosphorus can be removed simultaneously by phytoremediation because plants adsorb these nutrients through roots available for their growth [6].

Jirawan Torit

Division of Public Health, Faculty of Physical Education,

Srinakharinwirot University, Bangkok, Thailand
There was several researches investigated plants efficiency in nitrogen and phosphorus treatment. $\mathrm{X}$. Yu et al. [7] evaluated many species of plant was Schoenoplectuslacustris, Vetiveriazizanioides, Acoruscalamus, Canna indica, Zizanialatifolia, Phragmites communis, and Iris pseudacorus to remove nitrogen and phosphorus. C. Yan et al. [8] evaluated plants ability for nitrogen and phosphorus treatment, which was canna, iris, calla lily, dwarf papyrus, arrow arum, pickerelweed and bulltongue arrowhead.

Preliminary study investigated the efficiency of Acrostichumaureum L. to remove nitrogen and phosphorus from dormitory wastewater of university. Acrostichumaureum L., which is mangrove plant, had ability to remove nitrogen and phosphorus. The plant grew well in wastewater. Many researches studied aquatic plant to remove nitrogen and phosphorus. This study interested the perennial plant for nutrients treatment. The plant is Eucalyptus globulus Labill, which is no one, study to remove nutrients from wastewater. In addition, Eucalyptus globulus Labill is raw material to produce paper.

The aim of this study was comparison the efficiency of Acrostichumaureum L. and Eucalyptus globulus Labill in nitrogen and phosphorus treatment from dormitory wastewater of Srinakharinwirot University Ongkaruk. Sustainable system in nitrogen and phosphorus treatment was studied and plant biomass after nutrients treatment was also determined.

\section{Materials and Methods}

\section{A. Plant Preparation}

Acrostichumaureum L. and Eucalyptus globulus Labill. were prepared at $200 \mathrm{~g}$ and $400 \mathrm{~g}$ of fresh weight. Plants were cleaned and put in the pots that contained tap water for conditioning plants before using in the experiment. Then plants were used for nitrogen and phosphorus treatment at the greenhouse of Srinakharinwirot University Ongkaruk.

\section{B. Wastewater Preparation}

Wastewater was collected by composite sampling method from the effluent of Srinakharinwirot University Ongkaruk dormitory. 


\section{c. Nitrogen and Phosphorus Treatment by Acrostichumaureum L. and Eucalyptus globulus Labill.}

The plants were cultures in pots (12 inches in diameter). In the experiment comprised of $200 \mathrm{~g}$ of plants $+100 \mathrm{~g}$ of soil + 3 liters of wastewater, $400 \mathrm{~g}$ of plants $+100 \mathrm{~g}$ of soil +3 liters of wastewater, $100 \mathrm{~g}$ of soil +3 liters of wastewater, and only 3 liters of wastewater. Then wastewater was collected at day 1 , $3,5,7,9$, and 12 for determination nitrate nitrogen and phosphate concentrations by the cadmium reduction and the ascorbic acid colorimetric method, respectively [9].

\section{$D$. The Sustainability of the System in} Nitrogen and Phosphorus Treatment by Acrostichumaureum L. and Eucalyptus globulus Labill.

Nitrogen and phosphorus in the effluent of dormitory were treated by Acrostichumaureum L. and Eucalyptus globulus Labill for 4 cycles continuously. When ammonia-nitrogen and phosphate concentrations passed standard criteria of Pollution control department $\left(0.5 \mathrm{mg} \mathrm{L}^{-1}\right)$ and USEPA $\left(0.1 \mathrm{mg} \mathrm{L}^{-1}\right)$ [10], a new lot of wastewater was replaced in the system for study the sustainable treatment in the next cycle. Wastewater was sampled and determined ammonia-nitrogen, nitrate-nitrogen, and phosphate concentrations by the same method in section C.

\section{E. Biomass of Plants after Nitrogen and Phosphorus Treatment from Dormitory Wastewater for 4 Cycles}

Acrostichumaureum L. and Eucalyptus globulus Labill in the control and treatment systems were harvested after treatment for 4 cycles to determine the biomass. Then harvested plants were cleaned with distilled water and the fresh weight was recorded. After that the plant samples were oven dried at $65{ }^{\circ} \mathrm{C}$ to a constant weight. Then the plants were cooled in desiccators and the dry weight was measured [11].

\section{Results and Discussion}

\section{A. Phosphorus Treatment by Acrostichumaureum L. and Eucalyptus globulus Labill.}

Phosphorus treatment by Acrostichumaureum L. and Eucalyptus globulus Labill was studied for 4 cycles. The different plant weight was $200 \mathrm{~g}$ and $400 \mathrm{~g}$ of plants that were compared in phosphorus treatment. The result found that the system with plant was more efficiency phosphorus treatment than the system without plant. $200 \mathrm{~g}$ of Eucalyptus globulus Labill had better efficiency in phosphorus treatment than other systems. This result because the plant root characteristic is long and numerous. It can take up phosphorus in wastewater well. Phosphorus in wastewater promoted plant growth result in the plant grew well. Plant taken up phosphorus from wastewater in ortho-phosphate form available for their growth [12].

Phosphate concentration in the system with soil and wastewater was decreased. This result may be due to soil adsorption and microorganism role in wastewater [13]. Phosphate concentration was gradually decreased until passed standard criteria of USEPA $\left(0.1 \mathrm{mg} \mathrm{L}^{-1}\right)$ within 2 days in all cycle of the system with Eucalyptus globulus Labill (Fig 1-4). The result showed sustainable system of phosphorus treatment by Eucalyptus globulus Labill. Although Eucalyptus globulus Labill is perennial plant, it could treat phosphorus continuously and be healthy in wastewater. Phosphate concentration of the system with $400 \mathrm{~g}$ Eucalyptus globulus Labill was increased. The result due to plant decay effected phosphate release in the system.

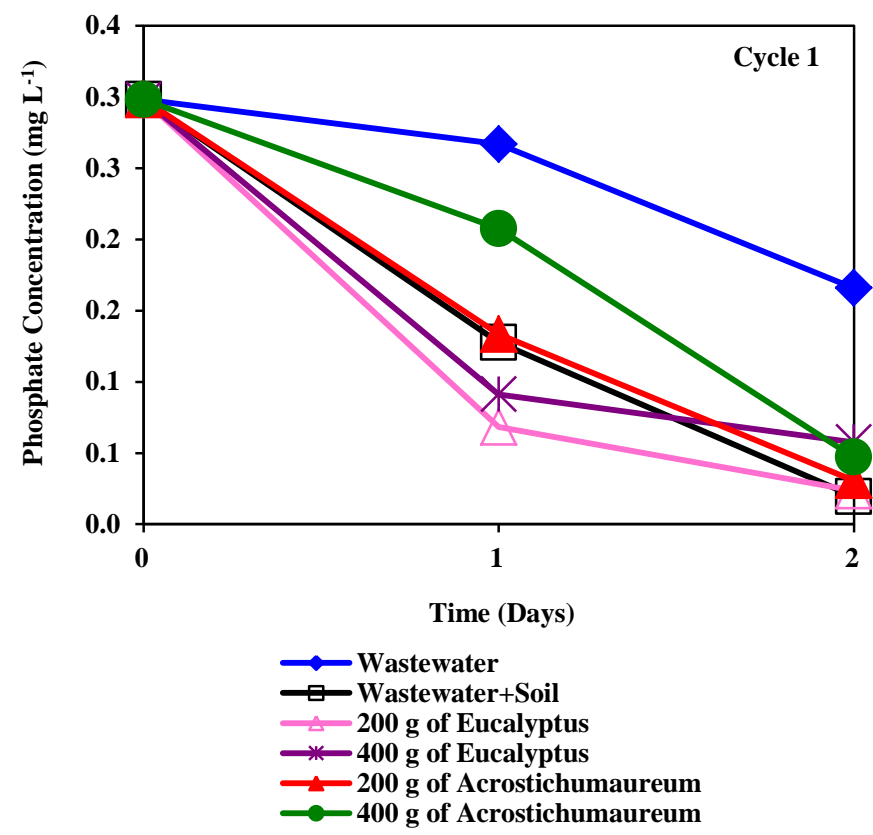

Figure 1. Phosphorus treatment by Acrostichumaureum L. and Eucalyptus globulus Labill in cycle 1

\section{B. Nitrogen Treatment by Acrostichumaureum L. and Eucalyptus globulus Labill.}

Nitrogen treatment by Acrostichumaureum L. and Eucalyptus globulus Labill was studied for 4 cycles. The result showed that nitrate-nitrogen in the system with plants was decreased (Fig 5-8). This result because plant taken up nitrogen from wastewater in nitrate form available for their growth [12]. However, nitrate-nitrogen in the system with soil and wastewater was decreased. This may be due to microorganism role in wastewater and soil or denitrification process [14]. The effect of nitrate-nitrogen decreased because of nitrification, denitrification, plant and microbial uptake in the system $[15,16]$. 
Proc. of the Third Intl. Conf. Advances in Bio-Informatics, Bio-Technology and Environmental Engineering- ABBE 2015 Copyright $(\odot$ Institute of Research Engineers and Doctors, USA .All rights reserved.

ISBN: 978-1-63248-060-6 doi: 10.15224/ 978-1-63248-060-6-70

Nitrate-nitrogen concentration in the system with $400 \mathrm{~g}$ of Eucalyptus globulus Labill was increased (Fig 6). The result because of plant dacay effected nitrate-nitrogen release in the system.

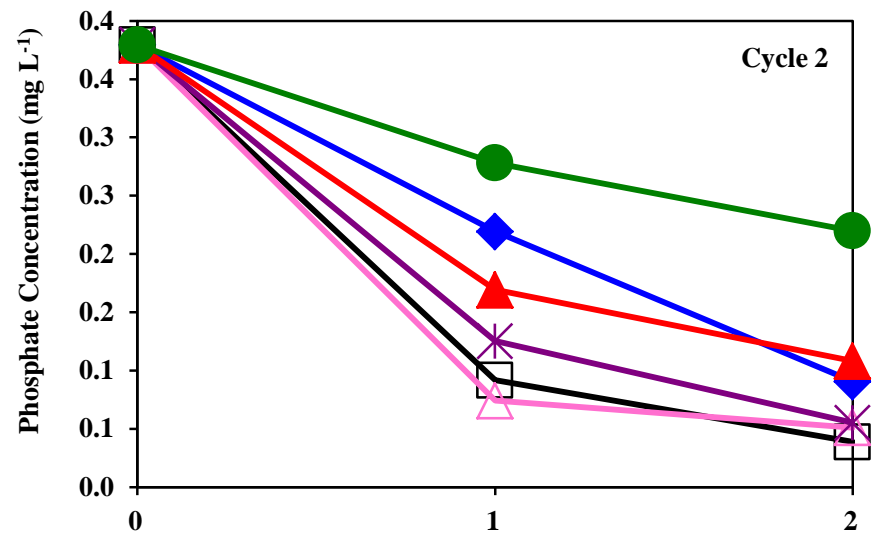

Time (Days)

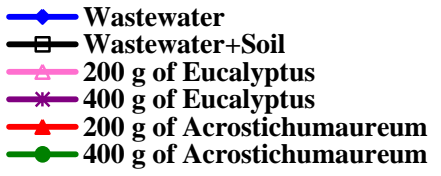

Figure 2. Phosphorus treatment by Acrostichumaureum L. and Eucalyptus globulus Labill in cycle 2
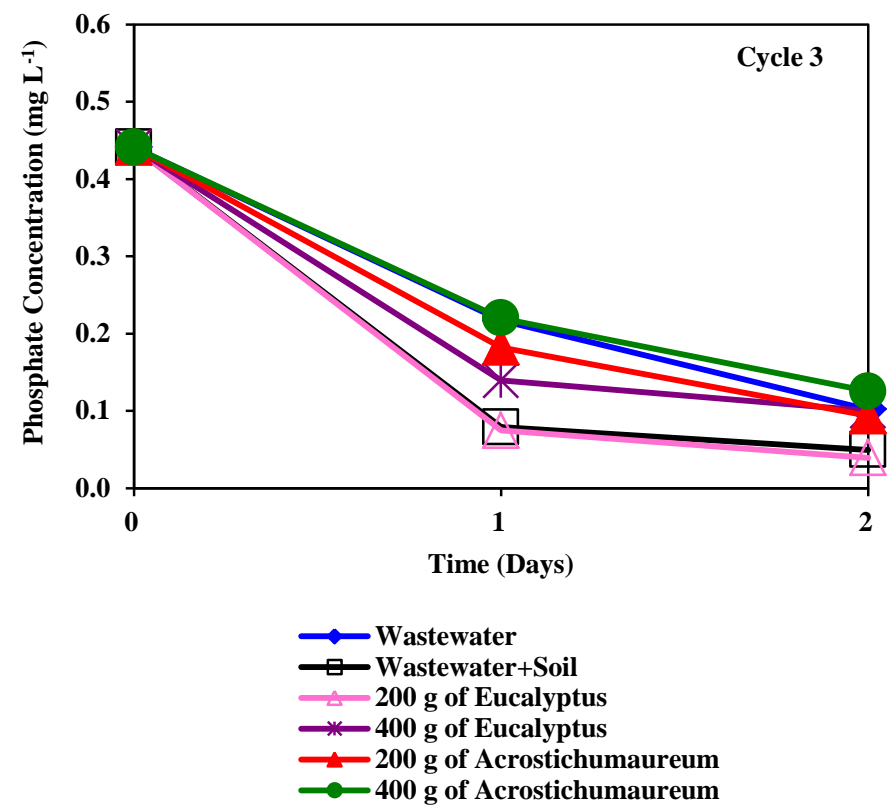

Figure 3. Phosphorus treatment by Acrostichumaureum L. and Eucalyptus globulus Labill in cycle 3

\section{Biomass of Plants before and after treatment wastewater for 4 cycles}

Acrostichumaureum L. and Eucalyptus globulus Labill grown in wastewater for 4 cycles (a month). Biomass of plants was determined after nitrogen and phosphorus treatment. The result found that plant biomass increased all treatments (Table 1). Plants grew well in wastewater because plant roots adsorbed nitrogen in nitrate form and phosphorus in orthophosphate form from wastewater available for their growth [14]. The shoots and the roots of both plants extended. This result indicated that nutrients in wastewater promoted plant growth [6]. The plants characteristic was healthy all experiment.

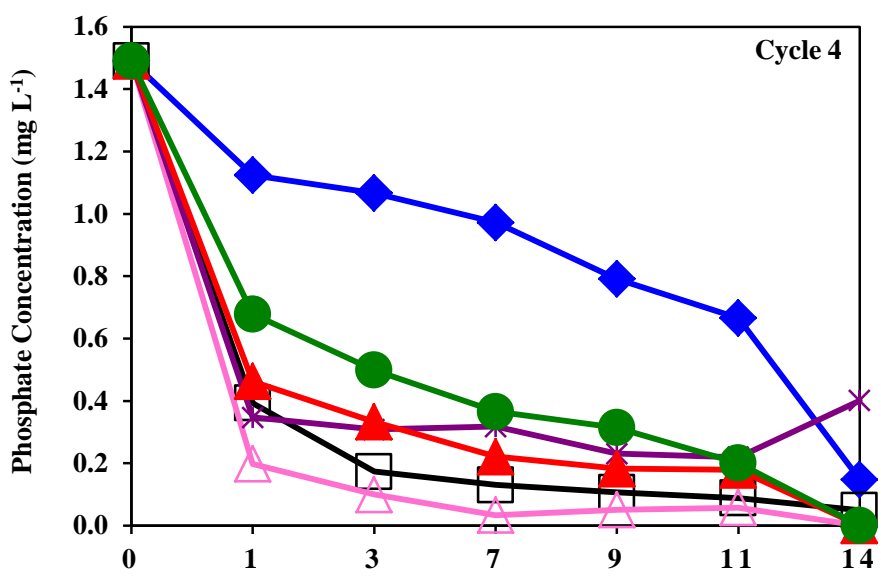

Time (Days)

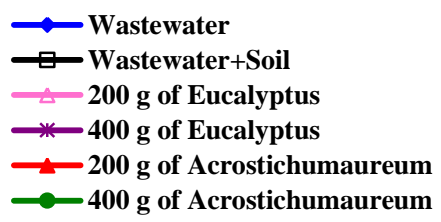

Figure 4. Phosphorus treatment by Acrostichumaureum L. and Eucalyptus globulus Labill in cycle 4
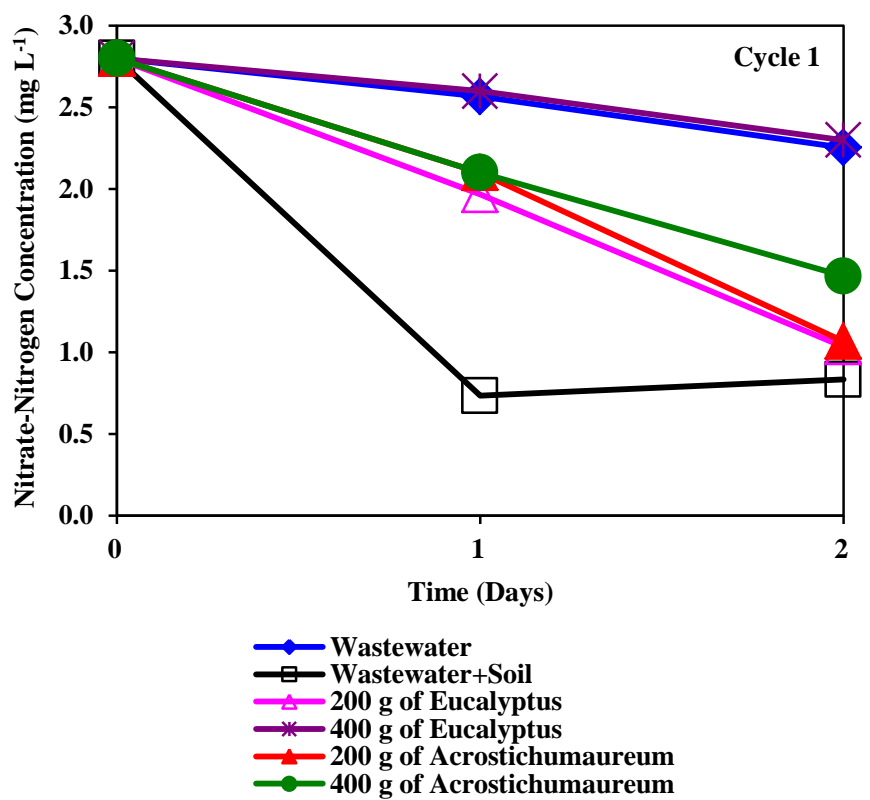

Figure 5. Nitrogen treatment by Acrostichumaureum L. and Eucalyptus globulus Labill in cycle 1 
Proc. of the Third Intl. Conf. Advances in Bio-Informatics, Bio-Technology and Environmental Engineering- ABBE 2015

Copyright $\odot$ Institute of Research Engineers and Doctors, USA .All rights reserved.

ISBN: 978-1-63248-060-6 doi: 10.15224/ 978-1-63248-060-6-70
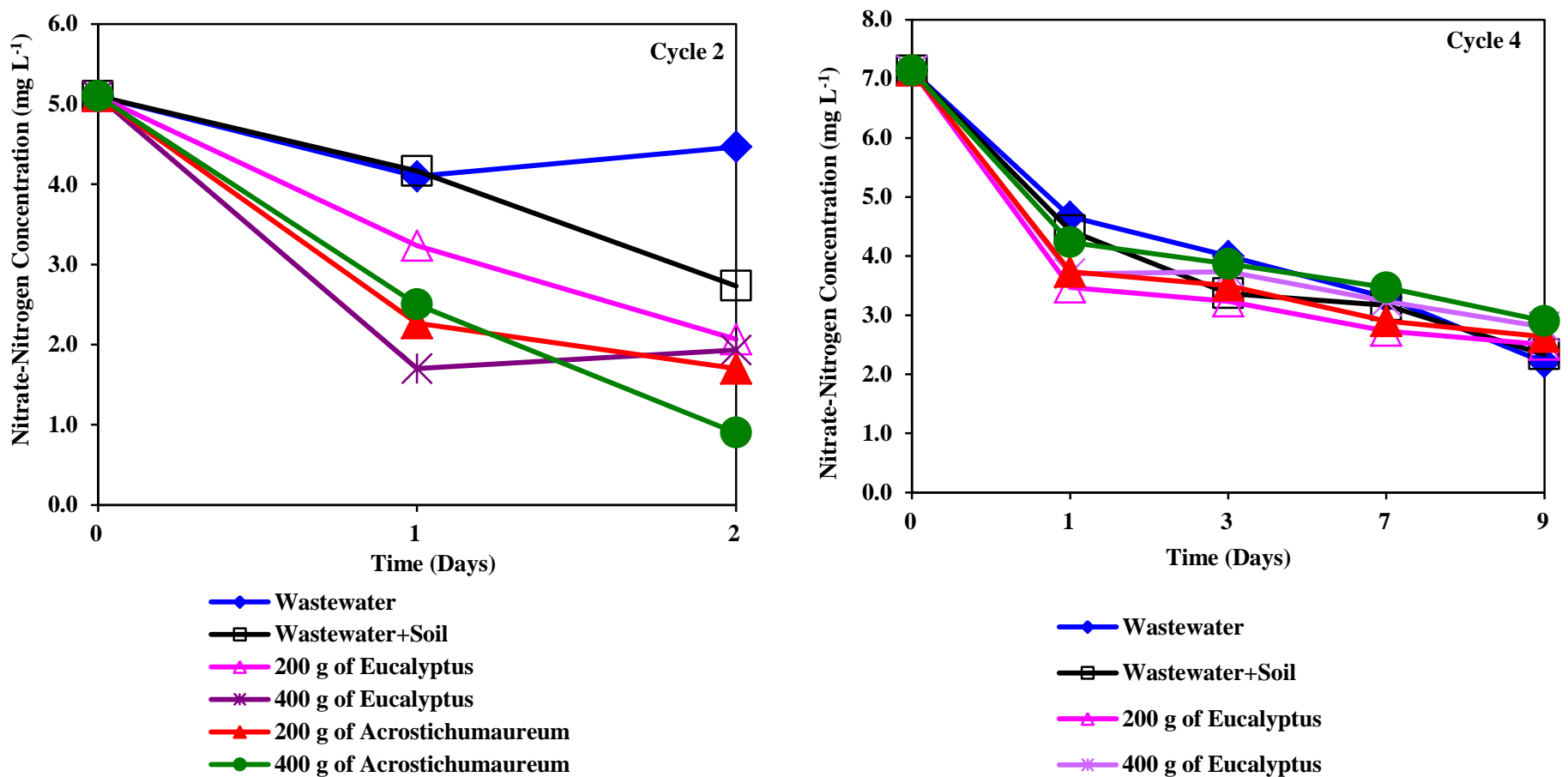

Figure 6. Nitrogen treatment by Acrostichumaureum L. and Eucalyptus globulus Labill in cycle 2

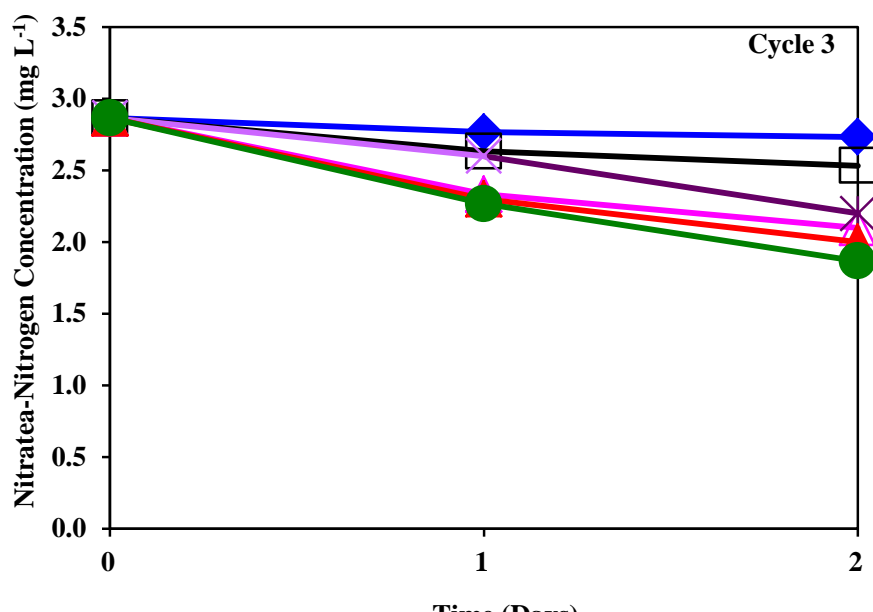

Time (Days)

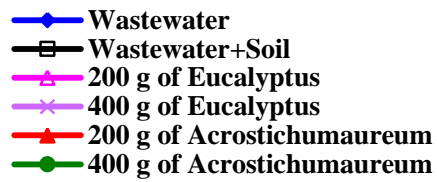

Figure 7. Nitrogen treatment by Acrostichumaureum L. and Eucalyptus globulus Labill in cycle 3

\section{Conclusions}

Nitrogen and phosphorus in dormitory wastewater of Srinakharinwirot University Ongkaruk were removed by using Acrostichumaureum L. and Eucalyptus globulus Labill. The best plant efficiency in nitrogen and phosphorus treatment was Eucalyptus globulus Labill at $200 \mathrm{~g}$ of plant weight. Plant taken up phosphorus and nitrogen from wastewater continuously through 4 cycles. The shoots and roots of plant had prolongation. Moreover, plant biomass after nitrogen and 
phosphorus treatment for a month was increased and plants were healthy all 4 cycles. Nitrogen and phosphorus in wastewater were removed by plant until passed standard criteria of USEPA and pollution control department within 2 days. This study indicated that Eucalyptus globulus Labill is the new selected plant for nitrogen and phosphorus treatment contaminated in wastewater simultaneously. Eucalyptus globulus Labill, which is perennial plant, suits to apply for wetland system.

\section{Acknowledgments}

The author would like to thank Faculty of Physical Education, Srinakharinwirot University, Thailand for financial support.

\section{References}

[1] J. Yin, P. Zhang, F. Li, G. Li, B. Hai, "Simultaneous biological nitrogen and phosphorus removal with a sequencing batch reactor-biofilm system," Int Biodeter Biodegr. http://dx.doi.org/10.1016/j.ibiod.2015.02.019.

[2] P.M. Nyenje, J.W. Foppen, S. Uhlenbrook, R. Kulabako, A. Muwanga, "Eutrophication and nutrient release in urban areas of Sub-Saharan Africa-A Review," Sci Total Environ., vol. 408, pp. 447-455, 2010.

[3] N.F. Gray, Biology of wastewater treatment, Imperial College Press Publishers, London, pp. 1-14, 2004.

[4] Y. Ouyang, "Evaluation of river water quality monitoring stations by principal component and factor analysis," Water Res., vol. 39, pp. 2621-2635, 2005.

[5] Q. Lu, Z. L. He, D. A. Graetz, P. J. Stoffella, and X. Yang, "Phytoremediation to remove nutrients and improve eutrophic stormwaters using water lettuce (Pistia stratiotes L.)," Environ. Sci. Pollut. R. vol. 17, pp. 84-96, 2010.

[6] K. Mengel, E. A. Kirkby, H. Kosegarten, T. Appel, Phosphorus, In: Principles of Plant Nutrition, eds. Kluwer Academic Publishers, Dordrecht, Boston, London, 2001.

[7] X. Yu, T. Konig, Z. Qi, G. Yongsheng, "Nitrogen and phosphorus removal of locally adapted plant species used in constructed wetlands in China," Water Sci Technol., vol. 66(4), pp. 695-703.

[8] C. Yan, B.P. Regina, O.D. Allen, "Nitrogen and phosphorus removal by ornamental and wetland plants in a greenhouse recirculation research system," HortScience, vol. 44, pp. 1704-1711.

[9] APHA-AWWA-WEF, Standard Methods for the Examination of Water and Wastewater, American Public Health Association, 1998.

[10] USEPA, "Quality Criteria for Water", United States Environmental Protection, USA, Rep 440, pp. 19-76023, 1976.
[11] P. Priya, S.V. Sahi, "Influence of phosphorus nutrition on growth and metabolism of Duo grass (Duo festulolium)," Plant. Physiol. Bioch., vol. 47, pp. 31-36, 2009.

[12] J.P. Nakas, C. Hagedorn, Biotechnology of PlantMicrobe Interaction, McGraw-Hill Publishing Company, New York.

[13] S. Sato and N.B. Comerford, "The non-recoverable phosphorus following sorption onto a Brazilian Ultisol", Biol Fert Soils, vol. 44, pp. 649-652, 2008.

[14] Wikipedia, the Free Encyclopedia, What is Nitrogen [Online],Available:http://en.wikipedia.org/wiki/Nitrogen [2010, September 10].

[15] C.C. Tanner, J. D’Eugenio, G.B. McBride, J.P. Sukias, K. Thompson, "Effect of water level fluctuation on nitrogen removal from constructed wetland mesocosms," Ecol. Eng, vol. 12(1), pp. 67-92, 1999.

[16] D.O. Huett, S.G. Morris, G. Smith, and N. Hunt, "Nitrogen and phosphorus removal from plant nursery runoff in vegetated and unvegetated subsurface flow wetlands," Water Res., vol. 39, pp. 3259-3272, 2005.

About Author:

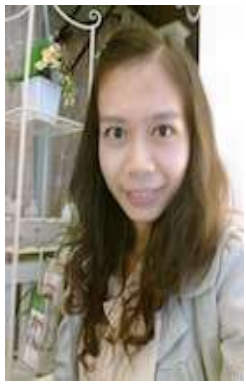

This research studied plants to clean up nitrogen and phosphorus from wastewater. The result found that Eucalyptus globulus Labill which is the perennial plant and the raw material to produce paper suit to apply for domestic wastewater treatment.

Jirawan Torit

Division of Public Health, Faculty of Physical Education, Srinakharinwirot University, Bangkok, Thailand 